http://dx.doi.org/10.5209/rev_ARAB.2016.v16.n1.49306

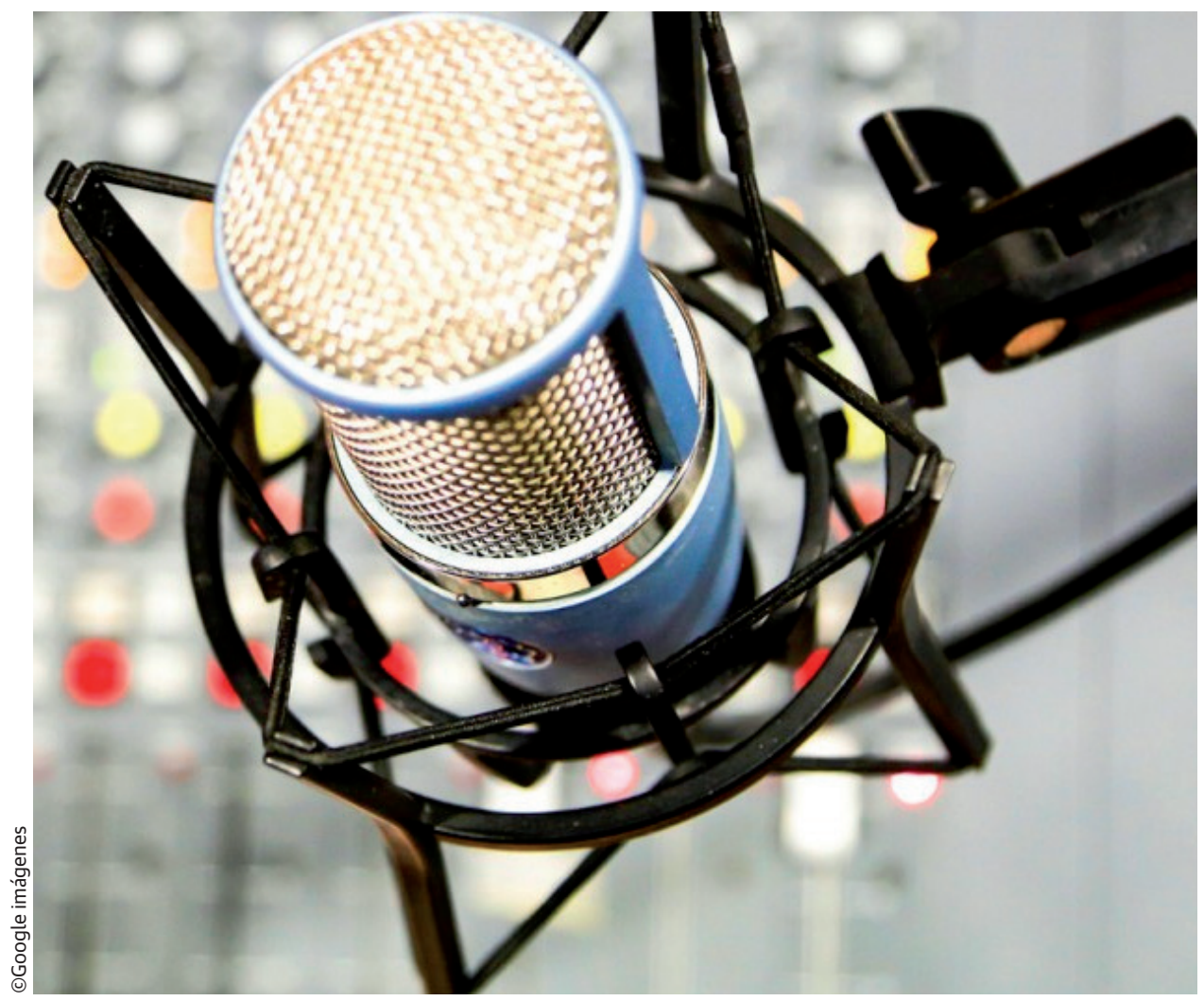

\title{
LA ESTRUCTURA EMOCIONAL DEL MENSAJE PUBLICITARIO EN RADIO
}

\author{
THE EMOTIONAL STRUCTURE OF THE \\ ADVERTISING MESSAGE IN RADIO
}

Lluís Mas Manchó / Lluis.Mas@upf.edu UNIVERSIDAD POMPEU FABRA 


\title{
RESUMEN
}

La publicidad radiofónica sufre una evidente crisis de creatividad al no haber encontrado su acomodo en un modelo de radio basado en la locución y el género informativo. Este artículo plantea la necesidad de utilizar la ruta periférica o heurística para captar y mantener la atención del receptor. En este marco, se propone la narrativa y la escenificación dramática como técnica persuasiva eficaz. El objetivo es diseñar una herramienta conceptual que pueda ser útil para idear una narración sonora al servicio de una determinada estrategia comercial. En primer lugar, se hace una revisión del poder persuasivo de la narración según las posibilidades del código sonoro. En segundo lugar, se desarrollan las claves escénicas y publicitarias (marca, producto, ventaja, beneficio y target) del mensaje sonoro. Y en tercer lugar, estas claves se incorporan en un modelo cuyo funcionamiento es pretestado mediante ocho casos de diferentes cuñas.

PALABRAS CLAVE

Publicidad radiofónica, persuasión narrativa, ruta periférica, representación escénica, estrategia

\begin{abstract}
Radio advertising is suffering from a remarkable crisis of creativity as it has yet not found its role in a radio model based on voice locution and information genres. This article suggests the need for implementing a peripheral or heuristic strategy to attract and hold listeners' attention. Within this framework, the narration and scene representation are proposed as suitable persuasion techniques. The objective is to design a useful conceptual tool for an efficient creative conception of narration at the service of certain commercial strategy. First, the concept of narrative persuasion is grounded according to the possibilities of the sound code. Second, the keys of scene representation and commercial strategy (brand, product, advantage, benefit and target) within the sound message are presented. And third, these keys are articulated in a model. This model is pre-tested by means of analyzing eight different case-radio ads.
\end{abstract}

KEYWORDS

Radio advertising, narrative persuasion, peripheral route, scene representation, strategy.

Recibido: 24 de junio de 2015

Aceptado: 25 de noviembre de 2015 


\section{INTRODUCCIÓN}

La publicidad radiofónica ha pasado por diferentes etapas desde la popularización del medio en la década de los años 30. Después de su edad de oro como soporte durante los años 30 y 40, la radio se vio relegada por la televisión en los años 60 y 70. En pleno siglo XXI, cuando todo apunta a la total convergencia mediática en terminales de Internet y a la publicidad personalizada y al servicio de la marca como actor social, los mensajes publicitarios clásicos y, en particular, la cuña radiofónica, continua existiendo. La renacida importancia del sonido en este contexto de marcas y experiencias sensoriales al servicio de intereses comerciales, puede y debe propiciar un replanteamiento de la creatividad sonora o radiofónica.

La publicidad radiofónica sufre desde hace años una importante crisis creativa, a nivel mundial y en España. La publicidad en este medio es víctima de una tradición radiofónica basada o bien en la información y en la voz, o bien en la radio-fórmula musical (Moreno Moreno, 2005; Perona Paez, Barbeito y Fajula, 2014). Este modelo clásico basado en un locutor-estrella que se representa a sí mismo en el espacio o de un estudio radiofónico y que trata temas de información desde una vertiente exclusivamente racional ha sido adoptado por la publicidad radiofónica desde hace décadas (Balsebre et al., 2006; Rodero, 2013).

Sin embargo, es bien sabido que el sonido es capaz de generar unas imágenes mentales de gran poder emocional. Una voz, un efecto, una música o un silencio pueden transportar al receptor a un lugar o situación, un estado, en compañía de alguien... El ser humano es un ser sonoro en una cultura visual. En cierto sentido, la radio tiene mayor capacidad de estimular la imaginación que la televisión (Schulberg, 1992; Betés Rodríguez, 2002: 41). Las imágenes de la televisión son concretas, mientras que las imágenes mentales de la radio son las que el receptor pueda imaginar ideal y subjetivamente, y durante más tiempo. De hecho, la imaginación precisa una negación del sentido de la vista: "soñamos" despiertos cuando cerramos los ojos, o cuando miramos pero no vemos. La radio no puede mostrar un producto, y por tanto no puede describirlo de una vez. Pero sí puede estimular la imaginación (descriptiva) de ese producto mediante su puesta en acción como parte de una narración.

Indudablemente, la radio de los últimos 30 años en España ha prescindido de esta gran capacidad del sonido y se ha dedicado a hablar a la audiencia desde la autoridad que confiere el micrófono y en un plano racional y puramente descriptivo (Muela, 2008). La radio arrastra el estigma de medio antiguo y pasado de moda (Rodero, 2008; Balsebre et al., 2006), especialmente entre los jóvenes. Indudablemente, este modelo se ha mantenido hasta la actualidad porque tiene su nicho de mercado basado en una producción barata y un posicionamiento dominante en determinados espacios, franjas horarias y segmentos poblacionales.

Perjudicada por la escasa capacidad imaginativa del medio, la publicidad no ha podido o no ha querido explorar nuevos caminos (Barbeito y Fajula, 2005; Rodero, 2008). La publicidad radiofónica se ha basado en un texto informativo leído "espontáneamente" por un locutor familiar. Sin embargo, el tipo de procesamiento racional con el que se decodifica el medio ha facilitado la rápida y fácil identificación de la publicidad por parte del oyente, y la consecuente desconexión de su atención. La publicidad radiofónica no ha reaccionado como el resto de iniciativas de comunicación comercial y sigue anclada en mensajes que intentan beneficiarse sin éxito de una ventaja competitiva que niega la misma naturaleza persuasiva de la publicidad. La publicidad en radio no ha podido aprovechar las ventajas de un medio creíble, personal e íntimo (Méndiz, 2001; Betés Rodríguez, 2002: 45), y barato técnicamente. Pero sí ha sufrido sus inconvenientes.

En este artículo se aborda la crisis de la creatividad publicitaria como víctima de un modelo estratégico, creativo y productivo basado en mensajes informativos, racionales, lineales y hablados. Y cuyo único recurso para captar la atención es el grito, el efecto o el golpe musical (Marcos, 2002). El objetivo es plantear los princi- 
pales criterios publicitarios y escénicos que debe seguir la creatividad sonora. Estos criterios se sitúan en un modelo que intenta articular ambos tipos de criterios de forma que el resultado sea un mensaje integrado y efectivo. Primero se hace una revisión del poder persuasivo de la narración según las posibilidades del código sonoro. En segundo lugar, se desarrollan las claves escénicas y publicitarias que el mensaje narrativo sonoro debe tener. Estas claves incluyen el rol de la marca, el producto, la ventaja, el beneficio y el target en el relato dramático. Y en tercer lugar, estas claves se integran en un modelo pretestado mediante unos ejemplos de mensajes publicitarios sonoros.

\section{LA PERSUASIÓN NARRATIVA SONORA}

Según la Elaboration Likelihood Model (ELM) de Petty y Cacioppo (1986), en aquellas situaciones en que la motivación o habilidad del receptor para recibir una información es baja, el tipo de procesamiento dominante será de tipo periférico o heurístico. Lo que empezó siendo una vía alternativa al procesamiento racional se ha convertido en la principal ruta para la publicidad tradicional. En la actualidad, construir un relato o narración es la clave de la eficacia persuasiva. De hecho, existen diferentes modelos que abordan la conexión entre la narración y la persuasión: el Transportation Imagery Model de Green y Brock (2002), el Extended Elaboration Likelihood Model (Slater y Rouner, 2002), y el Entertainment Overcoming Resistance Model (Moyer-Gusé, 2008). Según estos modelos, los procesos de implicación con los personajes, las situaciones, los contextos o las acciones constituyen una potente herramienta persuasiva.

En el caso de la publicidad radiofónica, parece relevante plantearse la ruta periférica como estrategia creativa de éxito. El gran problema de la publicidad en radio es el desvanecimiento de la atención cuando es reconocida, pues el usuario está cognitivamente preparado para seleccionar y discriminar los diferentes tipos de men- sajes. De forma lógica, para saltar esta barrera perceptiva, se debe entrar en la mente por la vía emocional. Ahora bien, esa estimulación emocional debe tener un sustento o justificación, en caso contrario la atención volvería a caer de inmediato. Es lo que ocurre si simplemente gritamos al oyente sin que ese grito tenga ninguna función representativa. Por tanto, el receptor necesita un proceso de absorción (Slater y Rouner, 2002) o transportación (Gerrig, 1993; Green y Brock, 2000, 2002; Moyer-Gusé, 2008) con aquello que se está contando.

Estimular la imaginación del receptor es activar la atención, pues significa implicar cognitivamente al receptor en el mensaje a través de procesos vicarios de identificación y proyección (De Graaf, Hoeken, Sanders y Beentjes, 2012; Rodero, Alonso González y Fuentes Abad, 2004). Para ello, el engagement con la narración debe basarse en un rápido planteamiento del estado inicial de la historia (De Graaf, Hoeken, Sanders y Beentjes, 2009; Busselle y Bilandzic, 2009).

El procesamiento heurístico del mensaje se debe producir en la modalidad discursiva narrativa y dramática del mensaje. Ahora bien, estas claves narrativas deben utilizar un código muy particular en tanto que exclusivamente sonoro. A pesar de la dominancia de la voz, el código sonoro incluye otros tres elementos: la música, los efectos y el silencio. La forma en que esta trama se convierte en historia en el medio radio es gracias al lenguaje que le es propio, el radiofónico, con el objeto de estimular la representación dramatizada de una escena (Alonso González, 2004). Por tanto, ni se caer en el reduccionismo de "leer" en radio un guión escrito de un anuncio en prensa, ni se puede contar con el gran poder sugestivo de la imagen. No obstante, los clásicos académicos Chion (1990) y Schafer (1994) pusieron en valor el poder comunicativo del código sonoro basado en la sucesión y la yuxtaposición de los cuatro elementos sonoros: la voz, la música, los efectos y el silencio. La creatividad publicitaria deberá explotar este código en su estrategia emocional para captar la atención (Wyse y Subramainan, 2012). 
En tanto que código comunicativo, el código sonoro se caracteriza por estar mediado tecnológicamente, ser natural y arbitrario simultáneamente, y ser voluntario (Rodríguez Bravo, 1998). La configuración de este código es cíclica y constante, pues tanto se pueden utilizar asociaciones ya existentes como crear nuevas. Estas asociaciones pueden tener diferentes niveles de naturalidad o iconicidad, o de arbitrariedad o simbolismo. Así, el sonido de un "portazo" se parece al sonido real de una "puerta cerrada con fuerza" y puede significar que alguien se ha ido dando un portazo literalmente. Pero ese portazo podría también representar la frustración por un amor perdido. Por tanto, la asociación entre significante sonoro y significado es flexible, múltiple y de grado, por lo que cualquier emisor decide, en función de su objetivo comunicativo, en qué medida el objeto sonoro puede ser más o menos natural (icónico) y más o menos arbitrario (simbólico), o serlo ambos a la vez a través de un proceso de acusmatización (Rodríguez Bravo, 1998). Por tanto, desde la aproximación semiótica de Eco (1975), el signo sonoro es, simultáneamente, icónico o natural, arbitrario o simbólico, e indicial. Se debe buscar constantemente asociaciones sonoras con los personajes, los movimientos o las situaciones (Varni, Volpe, Sagoleo, Mancini y Lepri, 2013).

El código sonoro es muy susceptible de ser explotado creativamente para promover la imaginación con constantes asociaciones nuevas. En la configuración de este código reside el reto creativo en radio, pues no es suficiente con hacer sonar un elemento o conjunto de elementos para representar una persona, objeto, espacio o situación, sino que se deben seleccionar aquellos elementos con función comunicativa y expresarlos mediante el lenguaje radiofónico (Balsebre, 1994; Guijarro y Muela, 2003). Los elementos sonoros de una escena pueden tener una función descriptiva, expresiva y narrativa (Rodero y Soengas, 2010). La selección deberá estar al servicio de la función comunicativa global, por lo que se tenderá a aglutinar funciones al servicio de una trama. Así, una escena sonora de una per- sona que sale de un espacio y se traslada a otro no precisará del sonido de la puerta. Sólo si la puerta es importante en la historia deberá tener presencia sonora. Y si lo es, entonces deberá sonar claramente y con todos los matices. Sólo así se conseguirá transmitir el significado previsto: un portazo a la pareja, a los virus, al invierno o al trabajo.

El triunfo de la imagen es describir por defecto, por lo que el guión se dedica a narrar. Ahora bien, toda narración contiene descripción, desvirtuada, precisamente, por la imagen. Y aquí es cuando se produce el triunfo del sonido: un lugar, un personaje o un objeto se autodescriben a través de la acción que los conecta, sin incongruencias con una imagen que es libre en la mente de los receptores.

\section{LA REPRESENTACIÓN ESCÉNICA}

La narración implica el relato de una historia basada en diferentes elementos escénicos y dramáticos: los personajes, la trama, los ambientes y el contexto narrativo.

\subsection{La construcción de personajes}

Greimas (1973) identifica los personajes como actantes de una trama en la que tienen una función muy precisa. En caso de no tener una función dramática clara, se convierten en prescindibles $\mathrm{y}$, por tanto, en fuente de ruido. En publicidad, urge superar los vicios narrativos a medio construir o mal construidos, que se resumen en el "encuentro casual entre dos conocidos, amigos o familiares, en la calle o en casa", y la recurrente "entrevista con un experto", sin ningún tipo de originalidad (Muela, 2012).

Un personaje no se construye automáticamente por aparición de una voz que se autodescribe como "imagen global" e inmediata de sí mismo, pues no estimularía un procesamiento imaginativo del personaje en cuestión. Por lo tanto, en radio, poner "ante los ojos de" es "ponerlo en acción", un acción familiar con las acciones cotidianas del target receptor (Green y 
Donahue, 2009). Aunque los personajes pueden ser reales, imitados o inventados, deben tener unos rasgos y unas actuaciones que los hagan identificables. El objetivo es conseguir que el oyente tome la perspectiva del personaje y se implique en lo que le ocurre (Murphy et al., 2011; Moyer-Gusé, 2008).

Los personajes son lo que dicen, lo que hacen y lo que suenan, Naturalmente, la construcción de personajes se hace, fundamentalmente, mediante la voz aunque no únicamente: "La voz es implícita definición” decía Rudolf Arheim; "la voz, por ser la expresión más etérea de la corporeidad, sugiere la definición de una imagen o de una persona con un cuerpo, una estética y un talante" (Rodero, 2005: 59). La voz nos hace imaginar el físico, la edad, la personalidad, el carácter, y el estado de salud físico y emocional del hablante mediante la expresión fonoestésica (Rodríguez Bravo, 1989). Se deben definir por tanto los datos sociodemográficos, físicos (constitución, color de piel o un rasgo físico que destaque, como la nariz), psicológicos (personalidad, gustos, deseos...) y sociales y culturales (trayectoria profesional, clase, nivel sociocultural...). Por tanto, los personajes se audodefinen al hablar en interacción, por el tipo de voz, por un sonido que los caracteriza (una respiración, una voz nasal, un gesto...) o por sus movimientos en acción.

La construcción vocal de los personajes se hace a través del registro de voz, la actitud vocal y la interpretación. Primero, todo personaje implica un registro de voz que lo individualiza. Según Clara Muela, existen los siguientes tipos de registros de voces (2001: 111): de trueno, campana, argentada, cálida, dulce, cascada, aguardentosa, atiplada y blanca. En segundo lugar, toda voz debe tener una actitud vocal en función del estado en el que se encuentre el personaje: alegre, triste, enfadado, impaciente, desganado... según el conjunto de factores que definen su vida, y que, si bien no se deben hacer explícitos, sí contribuyen a su implícita codificación. Y en tercer lugar, toda voz es interpretada en función del contexto en el que se halla el personaje. Naturalmente, el producto o marca debe ocupar un lugar protagonista en la trama. Por tanto, ese producto o marca deben constituirse en personajes o estar asociados a los personajes. La voz publicitaria es la voz del producto o de la marca. Por tanto, los personajes son el quien de la historia y el producto es el quien de la campaña publicitaria. Personaje y producto deben converger.

\subsection{La trama: el "storytelling"}

La trama es el leitmotiv o elemento cohesionador de la historia. Toda historia sigue el patrón estructural del relato clásico, esto es, el planteamiento nudo-desenlace (Wichmann, 2000). Ahora bien, esta estructura se ve matizada por la extrema brevedad del mensaje publicitario.

En primer lugar, el planteamiento se reduce a la mínima expresión, e incluso en ocasiones no existe, por lo que se pueden comenzar con un conflicto, un nudo o una situación inestable o sorprendente, aunque no se comprenda en todas sus dimensiones. Se puede tratar de una frase atractiva, misteriosa, provocativa o un recurso sonoro contundente que rompa con la monotonía y atraiga la atención. Ahora bien, ese elemento de llamada de atención debe formar parte de un nudo que deberá ser resuelto, y en el que la marca, el producto o el concepto de campaña serán protagonistas. Aunque con la mayor brevedad, el mensaje debe conseguir plantear un estado de las cosas y un conflicto del que el receptor desconoce su desenlace. Sólo así se conseguirá mantener la cohesión del relato y la atención de los receptores hasta el final (Hoeken y Sinkeldam, 2014). Con esta estructura de mínimos, se pueden aplicar las estructuras clásicas de la publicidad: problema-solución, tranche de vie, analogías, comparaciones, testimonios, etc.

En publicidad, todo mensaje debe estar al servicio de la estrategia comunicativa de la campaña. Así pues, la estructura narrativa de la historia es el "qué" del mensaje, por lo que se debe corresponder con la ventaja competitiva de la campaña. La trama es el "qué" de esa estrategia, es decir, el beneficio único que se quiere anunciar. Sólo así se conseguirá que la transportación narrativa vehicule el reason why 
(ventaja única) por el que se justifica el entretenimiento del receptor. El qué es la trama o historia que se quiere contar y es la ventaja competitiva del brief a partir del cual se idea esa trama.

\subsection{La recreación de ambientes}

Los efectos heurísticos de la narración se producen gracias a la implicación emocional de los receptores (Busselle y Bilandzic, 2009; De Graaf, Hoeken, Sanders y Beentjes, 2009; Murphy, Frank, Chatterjee y Baezconde-Garbanati, 2013). Vender emociones -alegría, tristeza, enfado...tiene un efecto catártico sobre el usuario (Dillard y Nabi, 2006; Dillard y Seo, 2013; Nabi, 2010). Pues bien, el principal beneficio de la publicidad actual es emocional. Green y Brock (2000) definen el engagement como aquellas situaciones que estimulan un proceso mental que atrae la atención, la imaginación y los sentimientos.

Es importante presentar unos ambientes y situaciones esencialmente emocionales para poder justificar la ventaja competitiva anterior (el por qué). El ambiente que se "respira" en una escena depende del conjunto de factores que la componen: espacio, tiempo, personajes, interacción... Ahora bien, nuevamente, esto se debe conseguir mediante el sonido. La codificación auditiva del ambiente requiere de una selección de elementos que tengan por función comunicar el tipo de ambiente de la dramatización. Gracias al componente arbitrario del código, se pueden crear metáforas auditivas que resuman de forma eficaz una situación. Existen determinados efectos, ambientes, golpes musicales, voces impostadas, sonidos no vocales... que por sí mismos tienen una gran fuerza comunicativa y dominan la interpretación del ambiente que se respira en una escena. Se trata de los efectos-símbolo, sonidos con un gran poder expresivo y narrativo (Wyse, 2004): el sonido de una cerveza que cae nos puede trasladar a una terraza veraniega, el ruido de unos cubiertos puede significar la soledad de alguien que come sólo, un silencio puede ser incómodo, un carraspeo puede indicar "presencia no conocida de alguien", etc. Esa situación emocional entre los personajes debe justifi- car el beneficio comercial que el receptor obtiene si compra el producto. Por tanto, la emoción del ambiente recreado es el "por qué" de la trama y el "por qué" de la ventaja competitiva anunciada.

\subsection{El contexto narrativo}

El contexto narrativo viene determinado por las dos dimensiones fundamentales: el espacio y el tiempo. En primer lugar, el espacio se refiere a los lugares comunes, esto es, aquellos escenarios típicos o tópicos reconocibles por el target a través del imaginario colectivo. Ahora bien, la creatividad publicitaria atañe a todas las dimensiones de la representación escénica y sin límites espaciales. Por tanto, ni siquiera es obligatorio tener un espacio físico; de hecho se puede tener un espacio no determinado ("no espacio", espacio cero o espacio virtual). Pero incluso si se trata de un espacio indeterminado, ese indeterminismo debe ser planificado y comunicado. No se puede tener a dos personajes interaccionando en un espacio no definido según una trama que implícitamente define un espacio definido.

Un espacio es la composición acústica de un conjunto de elementos sonoros con función comunicativa articulados según la trama definida. Por lo tanto, las interacciones y acciones de los personajes modificarán la forma en que se escuchan el resto de elementos, creando así la sensación espacial. Una clase se puede definir por el sonido al escribir en la pizarra (efecto-símbolo), por el sonido de un conjunto de ordenadores, por los pasos resonantes y rítmicos del profesor, por el susurro de los alumnos... El empleo de unos u otros depende de la perspectiva espacial adoptada (Rodríguez Bravo, 1998; Fuzellier, 1965)

En segundo lugar, el contexto narrativo también viene definido por el tiempo narrativo. El tiempo es un elemento ambiental o una parte de la acción. Como elemento ambiental, una escena puede estar definida por un momento determinado: un gallo significa el alba, unos grillos la noche, una música la primavera, etc. Y como parte de la acción, el tiempo narrativo se construye mediante los sonidos de esta acción (comer, la- 
var platos...) o la interacción (intercambio hablado, ritmo del habla, respiración, etc.). En ambos casos, nuevamente, se debe utilizar el lenguaje sonoro de forma integral (Pousa, 1999): el ritmo de la música, la presencia de elementos estridentes, el silencio, etc. Es más, el tiempo narrativo puede ser construido automáticamente si se corresponde con el tiempo real.

Además, la construcción del tiempo narrativo está totalmente conectada a la construcción del espacio. De hecho, la clave para imaginar una escena compleja dándole perspectiva y acción es la sincronización de los diferentes elementos sonoros en función de la acción y el espacio. En general, la cuadratura rítmica y melódica del conjunto de elementos sonoros que componen una pieza publicitaria (Gutiérrez y Perona Paez, 2002) crea una harmonía global de la unidad discursiva creada, como si se tratara de una canción, con los diferentes elementos sonoros del lenguaje radiofónico como instrumentos. Por ejemplo, si se pretende construir la escena de la llegada de un autobús, se puede hacer sonar un efecto de "puerta de bus abriéndose" y sincronizarlo con el aviso de un personaje sobre la apertura de dicha puerta: "apartaos". Además, la percepción humana tiende a buscar formas sonoras mediante la selección coherente de estímulos, por lo que a poco que haya un ritmo sonoro armonizado entre los diferentes elementos sonoros, se darán puntos de sincronización esporádicos e imprevisibles que contribuirán a la representación de la escena.

La construcción del espacio y el tiempo narrativo sitúan al producto o marca (el quien o personaje), ejerciendo la ventaja competitiva (el qué de la trama), en una situación con un claro beneficio emocional (el por qué del ambiente) y en un contexto familiar al target (el dónde, cuándo y cómo del contexto espacio-temporal).

\section{MODELO DE ANÁLISIS Y MÉTODO}

Este artículo se enmarca en la pregunta de investigación: ¿es posible articular de forma coherente los elementos estratégicos o variables de una campaña (marca, producto, ventaja, beneficio y target) con los elementos o variables dramáticas de una escenificación narrativa (personajes, acción, situación y contexto)?

Para dar respuesta a esta pregunta, aquí se propone un modelo o plantilla de análisis, testada cualitativamente y de forma exploratoria con 8 casos. Este análisis deberá complementarse en un futuro con estudios cuantitativos y de recepción.

Este sería el cuadro propuesto sobre el que se inscribirá la representación de las claves dramáticas de una escena (quien, qué, por qué y dónde/ cuándo/cómo) y las claves comerciales del mensaje publicitario sonoro (marca o producto, ventaja, beneficio y target). Estas segundas aparecen en cursiva en el análisis. En caso de carecer de algún rasgo, se utilizará el símbolo del conjunto vacío Ø (tabla 1):

En suma, el éxito de una cuña radiofónica según este modelo se basa en:

1. La marca o producto como protagonistas de la historia (marca/quién).

2. La ventaja competitiva debe ser explicada/justificada (ventaja/qué).

3. El beneficio debe justificarse emocionalmente como parte de la trama (beneficio/por qué).

4. El target se representa en contexto para identificacar (target/dónde, cuándo y cómo).

Tabla no 1. Esquema conceptual de ideación publicitaria. Fuente: propia

\begin{tabular}{|l|l|l|l|l|}
\hline & Quién & Qué & Porqué & Dónde/cuándo/cómo \\
\hline Marca Producto & $\mathrm{x}$ & & & \\
\hline Ventaja competitiva & & $\mathrm{x}$ & & \\
\hline Beneficio & & & $\mathrm{x}$ & \\
\hline Target & & & & $\mathrm{x}$ \\
\hline
\end{tabular}


Así, una marca puede ser directamente sonora (unos auriculares), o puede tener un producto que suena (un coche, una Harley o una lavadora), o estar representada por un personaje que habla (Steve Jobs, Matías Prats-ING,...).

En segundo lugar, se debe construir una escena dramática que verse sobre la ventaja competitiva (el "qué" de la historia). La ventaja competitiva de Fujitsu es el silencio de sus aires acondicionados, el de Foster's es el estilo de habla americano, el de un producto antitabaco puede ser una voz bien timbrada, el de Seat Ibiza es la música de Shakira y el de las patatas Bocabits es el crujir.

Esta ventaja se transforma, en tercer lugar, en un beneficio para el target. La anterior escena dramática tiene una justificación narrativa: el por qué o beneficio del producto (interesado, comercial) o de la trama (desinteresada, emocional). La voz ronca del tabaquismo puede ser confundida con el personaje Darth Vader, o el crujir de Bocabits puede ser un instrumento de una sinfonía clásica, etc. Y en cuarto lugar, el target debe quedar identificado por el conjunto de elementos sonoros y sobre todo por los elementos contextuales: el dónde, el cuándo y el cómo.

A continuación, se tratará de completar este modelo en el caso de ocho mensajes publicita- rios sonoros. Se trata de cuñas inéditas trabajadas en el ámbito universitario, y que debe servir de meros ejemplos para pretestar el modelo. Este análisis va a combinar una cuña con estrategia escénica siguiendo los patrones anteriores con una cuña que no los tiene en cuenta. El objetivo es comprobar si el modelo sirve para diferenciarlas. Para intentar evaluar el grado de coincidencia entre los elementos estratégicos (marca/ producto, ventaja, beneficio y target) y los elementos escénicos (quién, qué, por qué y dónde y cómo), los primeros aparecer en cursiva en el modelo.

\section{ANÁLISIS Y RESULTADOS}

En primer lugar, se muestra el análisis de la estrategia publicitaria radiofónica de una cuña sobre la marca Popitas (tabla 2). La escenificación dramática es la siguiente. Se escucha el efecto de cerrar el microondas y el pitido de activación (efecto), y a continuación tres voces manipuladas de forma muy exagerada hablan sobre actividades de ocio: ir al parque, ver el Barça, una película o un documental, un videojuego... Se caracterizan los personajes por el tipo de voz, lo que dicen

Tabla no 2. Modelo conceptual aplicado a la cuña 1. Fuente: propia

\begin{tabular}{|l|l|l|l|l|}
\hline Cuña 1 (Popitas) & Quién & Qué & Por qué & Dónde/Cómo \\
\hline Marca Producto & Popitas/palomitas & $\mathrm{X}$ & $\mathrm{X}$ & $\mathrm{X}$ \\
\hline $\begin{array}{l}\text { Ventaja compe- } \\
\text { titiva }\end{array}$ & $\mathrm{X}$ & $\begin{array}{l}\text { Palomitas para cual- } \\
\text { quier plan casero/Las } \\
\text { palomitas especulan } \\
\text { sobre el plan mien- } \\
\text { tras están dentro del } \\
\text { micro y van explo- } \\
\text { tando. }\end{array}$ & $\mathrm{X}$ & $\mathrm{X}$ \\
\hline Beneficio & $\mathrm{X}$ & $\mathrm{X}$ & $\begin{array}{l}\text { Palomitas rápidas y } \\
\text { fáciles/conversación } \\
\text { emocionada entre ellas } \\
\text { mientras estallan. }\end{array}$ & $\mathrm{X}$ \\
\hline Target & $\mathrm{X}$ & $\mathrm{X}$ & $\mathrm{X}$ & $\begin{array}{l}\text { Jóvenes que deciden } \\
\text { quedarse en casa } \\
\text { para ver una película } \\
\text { o cualquier otro entre- } \\
\text { tenimiento/dentro del } \\
\text { micro y en casa. }\end{array}$ \\
\hline
\end{tabular}


y su personalidad De repente suena la campana del micro y la puerta que se abre, y alguien que come una palomita.

Como se ve, en este caso, la marca y el producto son protagonistas de una trama en un espacio (microondas) y un tiempo determinados por la acción y por la interacción de unos personajes construidos en virtud de una ventaja coincidente con el qué de la trama, un beneficio emocional justificado por la situación y un contexto fácilmente identificable por el receptor target.

En paralelo, se presenta el esquema de estrategia publicitaria radiofónica para una cuña sobre el diario La Vanguardia (tabla 3). Este esquema se materializa con la siguiente escenificación dramática radiofónica. Una joven en un lugar no determinado le dice a alguien que "ha caído el muro", a quien un chico le responde “¿qué muro?”. La chica responde que el de Berlín, a lo que él le responde que no está al día y que coja La Vanguardia que acaba de comprar para informarse.

En contraste, en este segundo caso, La Vanguardia como marca y producto no tienen presencia en la historia hasta el final; no hay ventaja competitiva y el qué de la historia redunda en el beneficio. No hay situación emocionada (por qué) ni un espacio y tiempo definidos que permitan representar una escena creíble y estratégicamente eficaz.

En tercer y cuarto lugar, se presentan las marcas Meetic y Skype (tablas 4 y 5). La cuña de Meetic muestra a un joven duchándose. Acaba de ducharse y se pone frente al espejo, y, después de quitar el vaho con la mano, construye personajes con su voz y con una música descriptivo-expresiva de cada personaje (el seductor, el humilde, el maduro...). La música del personaje definitivo se convierte en narrativa (música clásica de culminación final) para comunicar que

Tabla no 3. Esquema conceptual aplicado a cuña 2. Fuente: propia

\begin{tabular}{|l|l|l|l|l|}
\hline Cuña 2 (La Vanguardia) & Quién & Qué & Por qué & Dónde/Cómo \\
\hline Marca Producto & La Vanguardia & X & X & X \\
\hline Ventaja competitiva & $\mathrm{X}$ & $\varnothing$ & $\mathrm{X}$ & $\mathrm{X}$ \\
\hline Beneficio & $\mathrm{X}$ & $\begin{array}{l}\text { Joven ignorante que ha leído } \\
\text { un diario del día después que } \\
\text { cayó el Muro de Berlín. }\end{array}$ & Mantenerse al día / Ø & $\mathrm{X}$ \\
\hline Target & Joven desinformada & $\mathrm{X}$ & $\mathrm{X}$ & $\mathrm{X}$ \\
\hline
\end{tabular}

Tabla no 4. Esquema conceptual aplicado a cuña 3. Fuente: propia

\begin{tabular}{|l|l|l|l|l|}
\hline Cuña 3 (Meetic) & Quién & Qué & Por qué & Dónde/Cómo \\
\hline Marca Producto & $\begin{array}{l}\text { Meetic/Alguien } \\
\text { que busca pareja }\end{array}$ & $\mathrm{X}$ & $\mathrm{X}$ & $\mathrm{X}$ \\
\hline Ventaja competitiva & $\mathrm{X}$ & $\begin{array}{l}\text { Encontrar cualquier tipo de } \\
\text { pareja/Un personaje mas- } \\
\text { culino ensaya delante del } \\
\text { espejo con diferentes regis- } \\
\text { tros y actitudes vocales }\end{array}$ & $\mathrm{X}$ & $\mathrm{X}$ \\
\hline Beneficio & $\mathrm{X}$ & $\mathrm{X}$ & $\begin{array}{l}\text { Relaciones íntimas/ } \\
\text { Construcción de la } \\
\text { imagen personal }\end{array}$ & $\mathrm{X}$ \\
\hline Target & $\mathrm{X}$ & $\mathrm{X}$ & $\mathrm{X}$ & $\begin{array}{l}\text { Joven liberal que busca } \\
\text { pareja/Joven en la ducha }\end{array}$ \\
\hline
\end{tabular}


ha conseguido crear el personaje adecuado, que no es otro que el de la persona que él es.

Esta cuña consigue crear una escena con un espacio bien definido (un baño concreto), y un tiempo determinado por la acción del protagonista, así como unos personajes definidos por la voz y la música (código sonoro). Como se ve, estos cuatro elementos son coincidentes con la marca, la ventaja propuesta y el beneficio y el tipo de target al que se dirige.

En paralelo, la cuña de Skype es simplista y descriptiva. Una voz de hombre explica que viaja mucho y que se siente sólo mientras se escucha la megafonía de un aeropuerto. De pronto admite tener una esperanza, momento en el que se escucha la música de Skype y las voces de sus hijos mientras entra la música final de la cuña.

Por tanto, en contraste con la anterior, la cuña de Skype no cuenta ninguna historia, sino que simplemente presente un personaje muy estereotipado que se siente sólo y hace una llamada a la familia. Por tanto, la cuña no hace coincidir a la marca o producto con el quién de la historia (la marca justifica de forma forzada la situación). La ventaja competitiva no está clara (podría llamar por Skype o mediante cualquier otra herramienta). Por último se construye el "espacio aeropuerto", pero sin adjetivar el aeropuerto o la parte en que el protagonista se encuentra.

En el quinto mensaje (tabla 6), se escucha una melodía instrumental de un móvil de bebé, interrumpida por un efecto de rebobinado y el lloro estridente de un bebé, mientras su joven padre le duerme poco a poco cantando y hablando. Se hace el silencio y vuelve el lloro estridente, esta vez seguido de una voz del padre más agresiva, que no consigue parar el lloro, y que acaba por expresar exabruptos enmascarados por un pitido.

Tabla nº 5. Esquema conceptual aplicado a cuña 4. Fuente: propia

\begin{tabular}{|l|l|l|l|l|}
\hline Cuña 4 (Skype) & Quién & Qué & Por qué & Dónde/Cómo \\
\hline Marca Producto & $\mathrm{X}$ & $\mathrm{X}$ & Sonido de Skype & $\mathrm{X}$ \\
\hline Ventaja competitiva & $\mathrm{X}$ & $\varnothing$ & $\mathrm{X}$ & $\mathrm{X}$ \\
\hline Beneficio & $\mathrm{X}$ & $\mathrm{X}$ & $\begin{array}{l}\emptyset / \text { Hablar por Internet } \\
\text { con la familia }\end{array}$ & $\mathrm{X}$ \\
\hline Target & $\begin{array}{l}\text { Empresario que } \\
\text { viaja mucho }\end{array}$ & Llama por Skype & $\mathrm{X}$ & $\begin{array}{l}\text { Padre que extraña a su } \\
\text { familia/Aeropuerto }\end{array}$ \\
\hline
\end{tabular}

Tabla nº 6. Esquema conceptual aplicado a cuña 5. Fuente: propia

\begin{tabular}{|c|c|c|c|c|}
\hline Cuña 5 (Durex) & Quién & Qué & Por qué & Dónde/Cómo \\
\hline Marca Producto & Durex/Pareja joven & $x$ & $x$ & $x$ \\
\hline Ventaja competitiva & $x$ & $\begin{array}{l}\text { La seguridad de un preser- } \\
\text { vativo/Lo poco deseable y } \\
\text { desagradable del lloro de } \\
\text { un bebé en plena noche a } \\
\text { oídos de los jóvenes. }\end{array}$ & $x$ & $x$ \\
\hline Beneficio & $x$ & $x$ & $\begin{array}{l}\text { La tranquilidad de no } \\
\text { tener hijos/Lo desa- } \\
\text { gradable del lloro de } \\
\text { un bebé por la noche }\end{array}$ & $x$ \\
\hline Target & $x$ & $x$ & $x$ & $\begin{array}{l}\text { Jóvenes de } 20 \text { años apro- } \\
\text { ximadamente que no se } \\
\text { plantean tener hijos/Jó- } \\
\text { venes que duermen por la } \\
\text { noche sin interrupciones }\end{array}$ \\
\hline
\end{tabular}


Como se ve en el modelo, los cuatro elementos estratégicos coinciden con los cuatro elementos dramáticos. Se muestran unos personajes en acción, con un tiempo que avanza y retrocede y un espacio muy claro.

Por lo que respecta a la cuña de Endesa (tabla 7), no hay una historia o trama, sino que una voz en off habla sobre la importancia de las farolas durante la noche mientras se escucha algún efecto eventual y descriptivo de la noche.

Por tanto, esta cuña no presenta a la marca o producto, y aunque la ventaja competitiva (la humanidad de la empresa) sí coincide con el qué de la trama, no tiene beneficio ni perfila el target. Por lo tanto, no hay conexión con los elementos estratégicos publicitarios.

A continuación, se analiza el caso de una cu- ña de Frenadol (tabla 8). En pleno invierno, con lluvia y truenos, una voz de un director de casting pide por megáfono en un espacio interior (voz filtrada) que "entre la siguiente". Se trata de una mujer con una voz muy congestionada que, después de decir nombre y número, se pone a recitar el personaje de Julieta. Ella es interrumpida por un emocionado y satisfecho director de casting, que ha confundido los efectos de un resfriado con una gran interpretación dramatizada de Julieta. Se corta la situación con el "frenazo" de Frenadol y el eslogan: "Desengáñate. Es muy poco probable que esto suceda. Frena tus síntomas con Frenadol”.

Esta cuña presenta una estructura en diagonal perfecta, pues el producto y la marca tiene una presencia totalmente protagonista -Julieta

Tabla no 7. Esquema conceptual aplicado a cuña 6. Fuente: propia

\begin{tabular}{|l|l|l|l|l|}
\hline Cuña 6 (Endesa) & Quién & Qué & Por qué & Dónde/Cómo \\
\hline Marca Producto & $\varnothing$ & $\mathrm{X}$ & $\mathrm{X}$ & $\mathrm{X}$ \\
\hline Ventaja competitiva & $\mathrm{X}$ & $\begin{array}{l}\text { Parte humana de la } \\
\text { empresa }\end{array}$ & $\mathrm{X}$ & $\mathrm{X}$ \\
\hline Beneficio & La luz & $\begin{array}{l}\text { La función de las fa- } \\
\text { rolas como acompa- } \\
\text { ñante en la noche }\end{array}$ & $\begin{array}{l}\varnothing / \text { Miedo de la } \\
\text { soledad nocturna }\end{array}$ & $\begin{array}{l}\text { Calle solitaria duran- } \\
\text { te la noche profunda }\end{array}$ \\
\hline Target & $\mathrm{X}$ & $\mathrm{X}$ & $\varnothing$ \\
\hline
\end{tabular}

Tabla no 8. Esquema conceptual aplicado a cuña 7. Fuente: propia

\begin{tabular}{|l|l|l|l|l|}
\hline Cuña 7 (Franadol) & Quién & Qué & Por qué & Dónde/Cómo \\
\hline Marca Producto & $\begin{array}{l}\text { Frenadol/ } \\
\text { No usuaria }\end{array}$ & $\mathrm{X}$ & $\mathrm{X}$ & $\mathrm{X}$ \\
\hline Ventaja competitiva & $\mathrm{X}$ & $\begin{array}{l}\text { Evitar la voz de congestión/ } \\
\text { Esa voz sólo puede servir } \\
\text { para hacer de Julieta en un } \\
\text { fragmento emotivo de la } \\
\text { obra de Shakespeare }\end{array}$ & $\mathrm{X}$ & $\mathrm{X}$ \\
\hline Beneficio & $\mathrm{X}$ & $\mathrm{X}$ & $\begin{array}{l}\text { Evitar que el resto } \\
\text { crea que lloramos/ } \\
\text { No parecer Julieta } \\
\text { de Shakesperare }\end{array}$ & $\mathrm{X}$ \\
\hline Target & $\mathrm{X}$ & $\mathrm{X}$ & $\mathrm{X}$ & $\begin{array}{l}\text { Personas que se ven afectadas } \\
\text { por el resfriado y con ese tipo } \\
\text { de síntomas/Mujer que se } \\
\text { presenta a un "casting" de } \\
\text { Romeo y Julieta }\end{array}$ \\
\hline
\end{tabular}


lo es por gracia de un resfriado que Frenadol evitaría, y la idea creativa responde a la necesidad de evitar esa voz de resfriado.

Y por último, en contraste, la cuña de Nespresso (tabla 9) presenta una voz en off explicando las bondades de la cafetera Nespresso con el único sonido de una cafetera, hasta que muy al final se escucha un desperezo de un chico quien pregunta a una chica que con quién habla.

Esta cuña carece de muchos elementos estratégicos (la marca o producto, la ventaja) y escénicos (el quién o protagonista o una mínima trama). Sólo crea un beneficio en un ambiente muy sencillo (café = mañana) y un target con rasgos muy generales. Esta cuña es la típica en que se reproduce el modelo radiofónico tradicional: una voz lee un texto publicitario sin que nada ocurra en un lugar no definido y sin tiempo narrativo.

\section{CONCLUSIONES}

El medio radio ha sobrevivido en España gracias a un modelo basado en la voz de grandes locutores, el prestigio y credibilidad del género informativo, y unas condiciones de recepción muy determinadas (franjas de mañana, y consumo radiofónico en el hogar, el trabajo o el coche). En este marco, el sonido como canal mediático de una sociedad permanentemente conectada tiene un futuro deslumbrante y lleno de posibilidades. Y la radio en sentido clásico seguirá teniendo su espacio vital. La publicidad, sin embargo, no encuentra su acomodo en este modelo clásico basado en un procesamiento racional, pues su propia naturaleza comercial es detectada automáticamente por el receptor. Por tanto, la publicidad radiofónica sufre una evidente crisis de creatividad.

Aquí se ha planteado la necesidad de utilizar la vía emocional para captar y mantener la atención del receptor. Para ello, se han desarrollado las claves de la representación escénica dramática en la que el canal auditivo posee ventajas únicas frente a cualquier otro tipo de representación. Esas ventajas giran alrededor de la imaginación o las imágenes mentales como recurso no contaminado por imágenes concretas. Sólo así se podrá alterar la racionalidad del continuum radiofónico y suscitar el interés del receptor.

Se ha hecho una revisión teórica de las reglas y los elementos claves para la representación dramatizada en radio. Y se ha propuesto un modelo de los pasos lógicos para la definición y diseño de una estrategia creativa para este medio. Se trata de un modelo basado en una estructura narrativa que equipara producto o marca con el quien de la narración, la ventaja competitiva con el qué, el beneficio con el por qué emocional de la situación, y target con el cuándo y dónde. Todo lo que no sea cumplir con estas igualaciones estará menoscabando o bien capacidad de procesamiento heurístico (transportación del receptor) o bien el papel comercial de los elemen-

Tabla no 9. Esquema conceptual aplicado a cuña 8. Fuente: Propia

\begin{tabular}{|c|c|c|c|c|}
\hline Cuña 8 (Nespresso) & Quién & Qué & Por qué & Dónde/Cómo \\
\hline Marca Producto & $\varnothing$ & $x$ & $x$ & $x$ \\
\hline Ventaja competitiva & $x$ & $\varnothing$ & $x$ & $x$ \\
\hline Beneficio & $x$ & $x$ & $\begin{array}{l}\text { La mañana como mo- } \\
\text { mento preferido por el } \\
\text { café/Alguien se des- } \\
\text { pierta por la mañana y } \\
\text { hace café }\end{array}$ & $x$ \\
\hline Target & $x$ & $x$ & $x$ & $\begin{array}{l}\text { Alguien joven/Un } \\
\text { chico se acaba de } \\
\text { despertar de buen } \\
\text { humor. }\end{array}$ \\
\hline
\end{tabular}


tos estratégicos. Así, debe haber una correspondencia entre los personajes (quién) y la marca o producto, la trama (qué) y la ventaja, la situación dramática de la trama (por qué) y el beneficio, y el espacio tiempo (cuándo y dónde) y el target. Este modelo ha sido pretestado con ocho casos (cuñas), en que se ha intentado encontrar la confluencia entre los cuatros elementos estratégicos y los cuatro elementos dramáticos. En cuatro de ellos se ha producido una total confluencia (modelo en diagonal) y en otros cuatros han faltado elementos o no ha habido confluencia entre ellos. Los primeros constituyen una representación escénica integral en función de la estrategia comercial sonora, mientras que los segundos muestran deficiencias perfectamente localizadas gracias a este modelo. Esa correspondencia, representada gráficamente por la diagonal del modelo, debe constituir el objetivo de los mensajes sonoros publicitarios que persigan persuadir por la ruta periférico o heurística.

Por tanto, este modelo puede ser una guía para trazar las líneas de una representación escénica radiofónica eficaz. Este modelo está inspirado en un pensamiento estratégico en torno al soni- do, de forma que se puedan reproducir las leyes perceptivas sonoras, basadas en la selección de estímulos y la coherencia perceptiva de formas. De hecho, los ejemplos utilizados muestran cómo el modelo contribuye a reconciliar los criterios estratégicos y comerciales con los elementos de creatividad sonora aquí desarrollados, de forma que no respetarlo deriva en un mensaje plano en el que no se estimula la imaginación y en el que se da un procesamiento deficiente del mensaje comercial.

Naturalmente, esta propuesta es meramente revisionista y exploratoria. Por tanto, el modelo necesita ser tomado como una hipótesis a ser testada en el futuro mediante una muestra grande de cuñas; así como en un estudio de recepción en el que se confirme la eficacia de los mensajes evaluados con la herramienta aquí propuesta. Aunque el modelo radiofónico tradicional tenga posibilidades de sobrevivir, la actual publicidad radiofónica deberá asumir como propias las tendencias mediáticas del sonido como plataforma (en eventos, sonorización de espacios, performances...) y aplicarlas al medio radio más tradicional. 


\section{BIBLIOGRAFÍA}

ALONSO GONZÁLEZ, Carmen María. El canto de las sirenas. Comunicación y persuasión en la publicidad radiofónica, Publicaciones Universidad Pontificia, Salamanca, 2004.

BALSEBRE, Armand, RICARTE, José María, PERONA PAEZ, Juanjo, ROCA, David, BARBEITO, Mari Luz y FAJULA, Anna. Los mitos de la publicidad radiofónica. Estrategias de la comunicación en la radio española, Madrid, Cátedra, 2006.

BALSEBRE, Armand. El lenguaje radiofónico, Cátedra, Madrid, 1994.

BARBEITO, Mari Luz y FAJULA, Anna. "La radio publicitaria: el peso del inmovilismo". Quaderns del CAC, Número 22 (2005), pp. 49-62.

BARBEITO, Mari Luz y VÁZQUEZ, Montse."La radio, un medio publicitario infravalorado". En La publicidad en la radio: VI Xornadas de comunicación social, Pontevedra: Universidad de Vigo, Facultad de Ciencias Sociales, Diputación Provincial, 2000, pp. 207-224.

BETÉS RODRÍGUEZ, Kety. "La ficción en la publicidad radiofónica. Ficción condensada, ficción fugaz". En I Jornada sobre Narrativa Radiofónica: Escribir con sonidos, dibujar con palabras, Universidad Complutense de Madrid, 23 de mayo de 2008.

BETÉS RODRÍGUEZ, Kety. El sonido de la persuasión. Relatos publicitarios en la radio, Universidad Cardenal Herrera CEU, Valencia, 2002.

BUSSELLE, Rick y BILANDZIC, Helena. "Measuring narrative engagement". Media Psychology, Volumen 12, Número 4 (2009), pp. 321-347. doi:http://dx.doi. org/10.1080/15213260903287259

CHION, Michel. Audio-vision; sound on screen. Columbia University Press, 1990.

DE GRAAF, Anneke, HOEKEN, Hans, SANDERS, José y BEENTJES, Hans. "The role of dimensions of narrative engagement in narrative persuasion". Communications, Volumen 34, Número 4 (2009), pp. 385-405. doi:10.1515/ COMM.2009.024.

DE GRAAF, Anneke, HOEKEN, Hans, SANDERS, José y BEENTJES, Hans (2012). "Identification as a mechanism of narrative persuasion". Communication Research, Volumen 39, Número 6 (2012), pp. 802-821. doi:10.1177/0093650211408594.

DILLARD, James Price y NABI, Robin L. "The persuasive influence of emotions in cancer prevention and detection messages". Journal of Communication, Volumen 56, Número S1 (2006), pp. S123-139. doi:10.1111/j.14602466.2006.00286.x.

DILLARD, James Price y SEO, Kiwon. "Affect and persuasion". En James PRICE DILLARD y Lijian SHEN (coord.), The Sage handbook of persuasion (pp. 150-166). Thousand Oaks, CA: Sage, 2013.
FUZELLIER, Etienne. Le langage radiophonique, IDHE, París, 1965.

GERRIG, Richard. Experiencing narrative worlds: On the psychological activities of reading. New Haven, CT: Yale University Press, 1993.

GUIJARRO, Toni y MUELA, Clara. La música, la voz, los efectos y el silencio en publicidad. La creatividad en la producción del sonido, Inversiones Editoriales Dossat, Madrid, 2003.

GREEN, Melanie C. y BROCK, Timothy C. "The role of transportation in the persuasiveness of public narratives". Journal of Personality and Social Psychology, Volumen 79, Número 5 (2000), pp. 701-721. DOI:10.1037//00223514.79.5.701.

GREEN, Melanie C. y BROCK, Timothy C. In the mind's eye: Transportation-imagery model of narrative persuasion. En M. C. Green, J. J. Strang yTimothy C. Brock (coord.), Narrative impact: Social and cognitive foundations (pp. 315-341). Mahwah, NJ: Erlbaum, 2002.

GREEN, Melanie C. y DONAHUE, J. Kevin. Simulated worlds: Transportation into narratives. En K. Markman,W. M. Klein y J. A. Suhr (Eds.), Handbook of imagination and mental simulation (pp. 241-254). New York, NY: Taylor \& Francis Group, 2009.

HERNÁNDEZ, María Isabel. El poder de la palabra en la publicidad de radio, Octaedro, Barcelona, 2006.

HOEKEN, Hans; SINKELDAM, Jop. "The Role of Identification and Perception of Just Outcome in Evoking Emotions in Narrative Persuasion". Journal of Communication, Volumen 64 (2014), pp. 935-955. http:// dx.doi.org/10.1111/jcom.12114

LÓPEZ i CAO, Carles. "Formes publicitàries a la ràdio. Un assaig de classificació", Quaderns del CAC, Número 4 (1999), pp. 61-64.

Marcos, Isabel. "Creatividad, viejas historias de la radio". Anuncios, Número 30 (2006).

MARTínEZ COSA, María Pilar y MORENO MORENO, Elsa (coords.). Programación radiofónica. Arte y técnica del diálogo entre la radio y su audiencia, Ariel Comunicación, Barcelona, 2003.

MÉNDIZ, Alfonso. "Una nueva comprensión de la radio como medio publicitario: posibilidades, estrategias y limitaciones de un medio sin imágenes". Reinventar la radio. Actas de las XV Jornadas Internacionales de la Comunicación, Eunate, Pamplona, 2001, pp. 143-155,

MORENO MORENO, Elsa. "Las 'radios' y los modelos de programación radiofónica". Comunicación y sociedad, Volumen XVIII, Número 1 (2005).

MORENO, Daniel. "La radio en crisis permanente", El publicista, Número 67 (2002).

MOYER-GUSÉ, Emily. "Toward a theory of entertainment persuasion: Explaining the persuasive effects of entertainment-education messages". Communication 
Theory, Volumen 18, Número 3 (2008), pp. 407-425. DOI:10.1111/j.1468-2885.2008.00328.x.

MUELA MOLINA, Clara. "La representación de la ficción en la cuña publicitaria. Personajes, contextos y otros elementos narrativos", Área abierta, Número 31 (2012).

MUELA MOLINA, Clara. "La representación de la realidad en la cuña publicitaria", Comunicación y sociedad, Volumen XXI, Número 2 (2008), pp. 115-139.

MUELA MOLINA, Clara. La publicidad radiofónica en España, Ediciones Internacionales Universitarias, Madrid, 2001.

MURPHY, Sheila, FRANK, Lauren, CHATTERJEE, Joyee y BAEZCONDE-GARBANATI, Lourdes. "Narrative versus nonnarrative: The role of identification, transportation, and emotion in reducing health disparities". Journal of Communication, Volumen 63, Número 1 (2013), pp. 116-137. doi:10.1111/jcom.12007.

MURPHY, Sheila, FRANK, Lauren, MORAN, Meghan Bridgid y PATNOE-WOODLEY, Paula. "Involved, transported, or emotional? Exploring the determinants of change in knowledge, attitudes, behavior in entertainment-education". Journal of Communication, Volumen 61, Número 3 (2011), pp. 407-431.

doi:10.1111/j.1460-2466.2011.01554.x.

$\mathrm{NABI}$, Robin L. "The case for emphasizing discrete emotions in communication research". Communication Monographs, Volumen 77, Número 2 (2010), pp. 153-159. doi:10.1080/03637751003790444.

PERONA PÁEZ, Juanjo, BARBEITO, Mari Luz y FAJULA, Anna. "Los jóvenes ante la sono-esfera digital: medios, dispositivos y hábitos de consumo sonoro", Comunicación y Sociedad, Volumen 27, Número 1 (2014), pp. 205-224.

PERONA PÁEZ, Juan José. "Formatos y estilos publicitarios en el prime-time radiofónico español: infrautilización y sequía de ideas", Zer, Número 23 (2007), pp. 219-242.

PETTY, Richard E., \& CACIOPPO, John T. "The elaboration likelihood model of persuasion". Advances in Experimental Social Psychology, Número 19 (1986), pp. 123-205.

POUSA, Xosé Ramon. "La publicidad como parte del discurso radiofónico". La publicidad en la radio. VI Jornadas de Comunicación Social, Universidad de Vigo, Pontevedra, 1999.

GUTIÉRREZ, Maria y PERONA PÁEZ, Juan José. Teoría y técnica del lenguaje radiofónico, Barcelona, Bosch, 2002.

GREIMAS, Algirdas J. Entorno al sentido, Madrid, Fragua, 1973.

RAJAR. Rajar Data Release. Reino Unido, 2015. URL: <http://www.rajar.co.uk/> [Consulta: el 20 de abril de 2015]
RODERO, Emma, MAS, Lluís, LARREA, Olatz y BLANCO, María. "Narrative elements in The Archers: An analysis of a long-running radio soap opera". En Madalena OLIVEIRA, Stachyra GRAZYNA y Guy STARKEY (coord.). Radio The Resilient Medium. Papers from the third conference of the ECREA Radio Research Section, Centre for Research in Media and Cultural Studies, University of Sunderland, Sunderland, pp. 169-178.

RODERO, Emma y SOENGAS PÉREZ, José. Ficción radiofónica: cómo contar una historia en la radio. Instituto Radio Televisión Española, 2010.

RODERO, Emma. "Publicidad sí, pero no radiofónica", Área Abierta, Número 20 (2008).

RODERO, Emma. Producción Radiofónica, Cátedra, Madrid, 2005.

RODERO, Emma, ALONSO GONZÁLEZ, C. M. y FUENTES $A B A D$, José Ángel. La radio que convence. Manual para creativos y locutores publicitarios, Ariel Comunicación, Barcelona, 2004.

RODRÍGUEZ BRAVO, Àngel. La dimensión sonora del lenguaje audiovisual, Paidos Comunicación, Barcelona, 1998.

RODRÍGUEZ BRAVO, Àngel. La construcción de una voz radiofónica, Tesis Doctoral, Departamento de Comunicación Audiovisual y Publicidad, Universidad Autónoma de Barcelona, 1989.

SCHULBERG, Bob. Publicidad radiofónica. El manual autorizado, Mc Graw Hill, Madrid, 1992.

SCHAFER, R. Murray. Our Sonic Environment and the Soundscape: The Tuning of the World. Rochester, Vermont: Destiny Books, 1994.

SLATER, Michael D., ROUNER, Donna y LONG, Marilee. "Television dramas and support for controversial public policies: Effects and mechanisms". Journal of Communication, Volumen 56, Número 2 (2006), pp. 235-252. DOI:10.1111/j.1460-2466.2006.00017.x.

VARNI, Gionvanna; GUALTIERO, Volpe; SAGOLEO, Roberto; MANCINI, Maurizio y LEPRI, Giacomo. Interactive reflexive and embodied exploration of sound qualities with BeSound. IDC'13 Jun 24-27 2013, New York, NY, USA ACM 978-1-4503-1918-8/13/06

WICHMANN, Anne (2000). Intonation in text and discourse. Essex: Pearson Education. ISBN: 0582234743

WYSE, Lonce y SUBRAMAINAN, Srikumar (2012). Foundations of interactive sound design for traditional storytelling. ICMC Non-Cochlear Sound.

WYSE, Lonce (2004). Contour Hierarchies, Tied Parameters, Sound Models and Music. Proceedings ICMC. http://www.zwhome.org/ lonce/Publications/ publications/contour-hierarchies-tied-parameterssound-models-and-music.pdf 